\title{
Comparing the Entrepreneurial Ecosystems for Technology Startups in Bangalore and Hyderabad, India
}

\author{
M H Bala Subrahmanya
}

\author{
"The emergence of [the] start-up wave in India is a relatively") \\ new phenomenon. India is today undergoing a fundamental \\ shift with entrepreneurship and innovation being primary \\ catalysts in job creation and solving everyday problems. \\ Praneeth Rao, Vaibhav Goyal, Agrima Singh, and Simrat Singh \\ International Policy Analysis Network Research Team
}

\begin{abstract}
Technology startups are gaining increasing attention from policy makers the world over because they are seen as a means of encouraging innovations, spurring the development of new products and services, and generating employment. Technology startups tend to thrive when inserted in a conducive entrepreneurial ecosystem. Therefore, ecosystem promotion is being given increasing policy support. However, the emergence and structure of entrepreneurial ecosystems for technology startups have hardly been traced and examined in detail. In India, Bangalore occupies a unique position in the startup world, and Hyderabad is fast emerging as one of the promising startup hubs in the country. Given this background, we set out to explore and examine the structure, evolution, and growth of ecosystems for technology startups in the context of Bangalore and Hyderabad. Both the ecosystems emerged due to the initial foundation laid in the form of government-industry-academia triple helix and their interactions leading to the emergence of a modern industrial cluster followed by an information technology and biotechnology cluster, which then led to R\&D cluster serving both the cities. These three clusters together, gradually and steadily, facilitated an entrepreneurial ecosystem for technology startups to emerge. The ecosystem operates within the triple helix model and has a nucleus with two outer layers: i) an inner layer of primary (indispensable) factors and ii) an outer layer of supplementary (secondary) factors. Through the analysis of the experiences of Bangalore and Hyderabad and their ecosystem evolution, its structure, and components, we derive key lessons for others within and beyond India.
\end{abstract}

\section{Introduction}

Entrepreneurial ecosystem development is a process occurring over a period of time. Successful ecosystems are highly developed and matured. The two often-cited benchmarks in this regard are Silicon Valley and Israel, which are uniquely identified for their success in entrepreneurship development and for generating in one year, more successful startups than any other nation would have done in years or decades (Arruda et al., 2013). If the structure of an ecosystem has to be understood for policy implications, it would be appropriate to probe how each ecosystem originated and developed over time, as this has not been adequately explored in the context of entrepreneurial ecosystems for technology startups, as of now (Motoyama \& Watkins, 2014).

Today, India has been recognized as one of the key potential sources of technology-based startups in the global economy (Gai \& Joffe, 2013), and it currently ranks third globally, in terms of number of existing startups and number of startup exits (NASSCOM, 2015; Times of India, 2016). Within India, its "Silicon Valley", Bangalore, was considered to be one of the nine Interna- 


\section{Comparing the Entrepreneurial Ecosystems for Technology Startups in India}

\section{H Bala Subrahmanya}

tional Startup Hubs outside the United States (Pullen, 2013). Further, recently it ranked 15th among the 20 cities with the best ecosystems for startups worldwide (Startup Genome, 2015). Hyderabad is one of the major upcoming startup locations in the country (NASSCOM, 2015), and it is a close competitor with Bangalore in the spheres of information technology, biotechnology, and R\&D-intensive industries (Das, 2015). Given this context, we set out to examine how these two ecosystems have emerged over time and to understand the prevailing structures of the ecosystems for technology startups in these two cities.

The emergence of technology startup hubs in both Bangalore and Hyderabad is a very recent phenomenon. However, the foundation for its emergence was laid decades ago, after India's independence in 1947. These two metropolitan cities host industrial clusters comprising modern manufacturing industries of varying sizes and are also home to several publicly-funded R\&D institutions and high-quality public and private educational institutions. Both cities have pro-industry regional governments, which have formulated and implemented regional (state-level) industrial policies periodically for the development of industries and infrastructure. Thus, both have the much needed industry-institute-government combination for the emergence of a conducive ecosystem for startups.

In this article, we trace the evolution of the entrepreneurial ecosystems in the two cities, with a historical perspective since India's independence, and we examine the current structures of these ecosystems. We aim to derive some general lessons from the experiences of these two technology startup hubs of India. But at the outset, we would like to broadly define the two important concepts of this article, namely, startups and ecosystems. A startup is, in general, defined as a new venture with no previous history of operations (Bala Subrahmanya, 2015). Such new ventures suffer from the liability of newness because they are unfamiliar and without any precedence (Certo, 2003). In terms of age, they are age-zero firms or "infants" (i.e., they are less than one-year old) (Kane, 2010). Startups exclude existing enterprises that have been acquired by new ownership, or those inherited by younger generations from the older ones, or "industry spin-offs" where a large firm has a control, directly or remotely, or franchisees of any form (Bala Subrahmanya, 2015). Similarly, an ecosystem in the context of startups, in general, may be defined as a system comprising prospective as well as currently operating startup entrepreneurs, their mentors, financiers, trainers, large firms that provide market support, organizations (universities, institutions, etc.), and government policy makers that support and promote startups, and their interrelationships and interactions.

\section{Objectives and Methodology}

This article has two specific research questions:

\section{How did the entrepreneurial ecosystems of Bangalore and Hyderabad emerge?}

\section{What are the structures and components of these en- trepreneurial ecosystems?}

To answer these questions, we first reviewed the relevant empirical literature and then conducted personal interviews with ecosystem stakeholders to understand the structure of the ecosystems and the interactions between the various actors.

Our empirical literature survey, which focused on the diverse components of entrepreneurial ecosystems in different parts of the global economy, clearly identified some common elements without which an entrepreneurial ecosystem may not come into existence or may not be effective and successful. The key elements or components of an entrepreneurial ecosystem identified and emphasized by the various empirical studies are presented in Table 1.

Based on the literature survey, and our identification of key stakeholders under different domains of the entrepreneurial ecosystems in both Bangalore and Hyderabad, we prepared an open-ended questionnaire and identified a set of about 50 stakeholders for each city. We approached those identified stakeholders who responded positively to our request and interviewed each one of them personally (51 in Bangalore and 38 in $\mathrm{Hy}-$ derabad) for about one and half hours during the period from August 2015 to January 2016 (Table 2). An open-ended questionnaire formed the basis of the interviews, which contained 10 questions covering topics such as:

- definition of a high-tech startup

- characteristics of a high-tech startup

- components of an ideal ecosystem for high-tech startups (in India)

- ranking of the identified components 


\section{Comparing the Entrepreneurial Ecosystems for Technology Startups in India}

\section{H Bala Subrahmanya}

Table 1. The entrepreneurial ecosystem: components and their roles

\begin{tabular}{|c|c|c|c|}
\hline No. & Components & Role and Importance & Identified Studies \\
\hline 1 & Entrepreneurship & $\begin{array}{l}\text { At the core of the ecosystem for the birth, growth, and } \\
\text { exit of startups. }\end{array}$ & $\begin{array}{ll}\text { - } & \text { Isenberg (2011) } \\
\text { - } & \text { Feld (2012) }\end{array}$ \\
\hline 2 & Markets & $\begin{array}{l}\text { Early product adopters, repeat customers, networks, } \\
\text { and multinational corporations. }\end{array}$ & - Arruda et al. (2013) \\
\hline 3 & Finance & $\begin{array}{l}\text { Angel investors, private equity firms, venture } \\
\text { capitalists, public capital markets for initial public } \\
\text { offerings, and debt instruments. }\end{array}$ & $\begin{array}{l}\text { - } \quad \text { Foster \& Shimizu (2013) } \\
\text { - } \quad \text { Piscione (2013) }\end{array}$ \\
\hline 4 & Human Resources & $\begin{array}{l}\text { Labour force, technical workforce, and managerial } \\
\text { talent. }\end{array}$ & $\begin{array}{ll}\text { - } & \text { Anjum (2014) } \\
\text { - } & \text { Dale \& Zell (2014) }\end{array}$ \\
\hline 5 & $\begin{array}{l}\text { Education \& } \\
\text { Research }\end{array}$ & $\begin{array}{l}\text { Institutions that produce non-graduate and graduate } \\
\text { workforce, technical and managerial talent, } \\
\text { innovations, entrepreneurial training, etc. }\end{array}$ & $\begin{array}{ll}\text { - } & \text { WEF (2014) } \\
\text { - } & \text { Bala Subrahmanya (2015) } \\
\text { - } & \text { Stangler \& Masterson (20] }\end{array}$ \\
\hline 6 & $\begin{array}{l}\text { Government } \\
\text { (regulatory } \\
\text { framework \& } \\
\text { policies) }\end{array}$ & $\begin{array}{l}\text { Favourable laws and regulations for tax incentives, } \\
\text { venture capital, bankruptcy, property rights, labour, } \\
\text { and exits public research institutions. }\end{array}$ & $\begin{array}{ll}\text { - } & \text { Krajcik \& Formanek (2015 } \\
\text { - } & \text { Sean (2015) } \\
\text { - } & \text { Haines (2016) }\end{array}$ \\
\hline 7 & $\begin{array}{l}\text { Large Companies } \\
\text { (including } \\
\text { multinational } \\
\text { corporations) }\end{array}$ & $\begin{array}{l}\text { As customers, sources of entrepreneurship, nurturers } \\
\text { of startups through accelerators, sources of technical } \\
\text { and managerial workforce, investors, technology } \\
\text { providers, acquirers of startups. }\end{array}$ & $\begin{array}{l}\text { - Hemmert et al. (2016) } \\
\text { - Aaltonen (2016) }\end{array}$ \\
\hline 8 & Mentors/Advisors & $\begin{array}{l}\text { Technical and managerial advice for startup creation, } \\
\text { stability, growth, and exits. }\end{array}$ & \\
\hline 9 & $\begin{array}{l}\text { Support } \\
\text { Institutions }\end{array}$ & $\begin{array}{l}\text { Accelerators, technology business incubators, soft } \\
\text { infrastructure (e.g., professionals such as lawyers and } \\
\text { accountants), and hard infrastructure (e.g., } \\
\text { telecommunications, transportation, and logistics) }\end{array}$ & \\
\hline 10 & Cultural Support & $\begin{array}{l}\text { Tolerance of risk, failures, support for innovation, } \\
\text { creativity, drive and hunger for achievements; higher } \\
\text { social status for entrepreneurs; respect for wealth } \\
\text { creation. }\end{array}$ & \\
\hline 11 & Media & $\begin{array}{l}\text { Publicizing: startup creations, its pre-requisites, } \\
\text { support available, failure consequences, and } \\
\text { achievements of success }\end{array}$ & \\
\hline 12 & $\begin{array}{l}\text { Immigration of } \\
\text { Talent }\end{array}$ & $\begin{array}{l}\text { Sources of entrepreneurship, human resources, } \\
\text { advisors/mentors, finance, support networks, etc. }\end{array}$ & \\
\hline
\end{tabular}




\section{Comparing the Entrepreneurial Ecosystems for Technology Startups in India}

\section{H Bala Subrahmanya}

Table 2. Entrepreneurial ecosystem stakeholders in Bangalore and Hyderabad interviewed for this study

\begin{tabular}{lcc}
\hline StakeholderType & Bangalore & Hyderabad \\
\hline Startup Entrepreneurs & 17 & 17 \\
\hline Government Officials & 1 & 1 \\
\hline $\begin{array}{l}\text { Large Enterprises } \\
\text { (multinational corporations } \\
\text { and domestic large firms) }\end{array}$ & 7 & 2 \\
\hline $\begin{array}{l}\text { Professors } \\
\text { Financiers (angels, venture } \\
\text { capitalists, etc.) }\end{array}$ & 7 & 6 \\
\hline
\end{tabular}

\begin{tabular}{lcc}
$\begin{array}{l}\text { Accelerators, Incubators, and } \\
\text { Co-Working Spaces }\end{array}$ & 7 & 6 \\
\hline Industry Associations & 3 & 1 \\
\hline Mentors & 3 & 1 \\
\hline Media Representatives & 3 & 0 \\
\hline Total & $\mathbf{5 1}$ & $\mathbf{3 8}$
\end{tabular}

- the importance of quality of components, quantity of components, and interaction among components for determining the effectiveness of an ecosystem

- whether Bangalore/Hyderabad has the best ecosystem in India

- factors that led Bangalore/Hyderabad to emerge as one of the best startup hubs in India

- significant components of the ecosystem for hightech startups in Bangalore/Hyderabad

- components that are lacking or have a weaker presence in Bangalore/Hyderabad

- the level of interaction between the components in the ecosystem of Bangalore/Hyderabad

The author took down notes as he interacted with the stakeholders of the ecosystem. The information gathered through the personal interviews and the review of relevant literature formed the basis of the analyses to answer the two research questions.

\section{Phases of Evolution in the Entrepreneurial Ecosystems of Bangalore and Hyderabad}

Both Bangalore and Hyderabad are the capital cities of their respective states, namely, Karnataka and Andhra Pradesh/Telangana in southern India. These are two of the metropolitan cities of India and are industrial/commercial/institutional hubs of the country. According to the Jones Lang LaSalle City Momentum Index (ClarkeBillings, 2017), Bangalore is the most dynamic city in the world whereas Hyderabad is the fifth most dynamic city in the world. Table 3 provides some key statistics on both of these cities.

After India's independence in 1947 (for Bangalore) and after the integration into Indian Union in 1948 (for Hyderabad), the foundation for the evolution of an entrepreneurial ecosystem was laid in both the cities. This was primarily driven by public policies initiated by the national government and were characterized by the location and growth of central public sector undertakings (CPSUs) followed by industrial estates for modern small-scale industries and establishment of national government-funded public R\&D institutions, as well as public and private educational institutions (Department of Gazetteer, 1996; Sudhira et al., 2007). This foundation resulted in the emergence of the muchneeded regional innovation system, led by the "triple helix" comprising university-industry-government and their interactions, as propounded by Etzkowitz (2003). In the triple helix model, the State (national government) played a dominant role, driving industry and academia for national/regional development, resembling what Etzkowitz and Leydesdorff have described as a "statist" model (2000). The development of such a regional innovation system occurred over a period comprising almost four decades, ranging from the late 1940s to the mid-1980s. This marked the first phase in the evolution of an entrepreneurial ecosystem in both the cities (Figures $1 \& 2$ ).

The transition from the first phase to the second phase occurred rather smoothly and spontaneously beginning in the mid-1980s in Bangalore, with the entry of Texas Instruments and the origin of Bangalore-based information technology firms. The process was stimulated by the introduction of national economic reforms in 1991 and their acceleration since then, which virtually removed the entry barriers for multinational corporations in the information technology industry. This, coupled with the initiatives of regional government to strengthen the physical and virtual infrastructure as well as educational institutions, Bangalore received a 


\section{Comparing the Entrepreneurial Ecosystems for Technology Startups in India}

\section{H Bala Subrahmanya}

Table 3. Bangalore and Hyderabad: comparative statistics

\begin{tabular}{|c|c|c|}
\hline Characteristics & Bangalore & Hyderabad \\
\hline Year of Founding & 1537 & 1591 \\
\hline Area & $741 \mathrm{~km}^{2}$ & $650 \mathrm{~km}^{2}$ \\
\hline Altitude Above Sea Level & $920 \mathrm{~m}$ & $550 \mathrm{~m}$ \\
\hline Climate & $18^{\circ} \mathrm{C}-38^{\circ} \mathrm{C}$ & $15^{\circ} \mathrm{C}-40^{\circ} \mathrm{C}$ \\
\hline Population & 8.4 million & 7.7 million \\
\hline Literacy Rate & $89 \%$ & $83 \%$ \\
\hline Major Industries & $\begin{array}{l}\text { Information technology and } \\
\text { biotechnology industries, } \\
\text { manufacturing, and textiles }\end{array}$ & $\begin{array}{c}\text { Information technology and } \\
\text { biotechnology industries, and } \\
\text { manufacturing }\end{array}$ \\
\hline Universities and Institutes of National Importance & 13 & 6 \\
\hline $\begin{array}{l}\text { Central Government Institutes and Central Public } \\
\text { Sector Undertakings }\end{array}$ & 57 & 47 \\
\hline $\begin{array}{l}\text { State Government Institutes and State Public Sector } \\
\text { Undertakings }\end{array}$ & 20 & 13 \\
\hline $\begin{array}{l}\text { Scientific \& Industrial Research Organizations } \\
\text { (SIROs) }\end{array}$ & 35 & 32 \\
\hline DSIR-Registered Private Sector In-House R\&D Units & 178 & 185 \\
\hline Private Sector R\&D Units Not Registered with DSIR & 104 & 79 \\
\hline $\begin{array}{l}\text { Notes: } \\
\text { 1. Population numbers and literacy rate percentages: Office of the Registrar Gener } \\
\text { 2. Bangalore year of founding, area, altitude, and climate: Sudhira et al. (2007). } \\
\text { 3. Hyderabad year of founding, area, altitude, and climate: Das (2015). } \\
\text { 4. Data on universities, government institutes, public sector undertakings, SIROs, } \\
\text { 5. DSIR - the Department of Scientific \& Industrial Research - is a part of the Minis } \\
\text { industries, and it grants recognition to in-house R\&D units in industrial enterprise }\end{array}$ & $\begin{array}{l}\text { ensus Commissioner, India (2011) } \\
\text { egistered R\&D units, and private sector R\&D } \\
\text { Science \& Technology, Government of India. } \\
\text { vided they satisfy terms and conditions as stat }\end{array}$ & $\begin{array}{l}\text { (2015). } \\
\text { ISy endeavour of DSIR is to promote R\&D by the }\end{array}$ \\
\hline
\end{tabular}

boost to emerge as an information technology industry cluster, soon compounded by a biotechnology industry cluster, by the late 1990s. With the introduction and acceleration of national economic reforms, the role of the State (national government) declined in intensity, though regional government continued to be important, and the role of industry and academia became more important. Thus, in the triple helix model, all the three partners, namely, State, Academia, and Industry seemed to emerge as equally important, thereby resembling the "laissez-faire" model described by Etzkowitz and Leydesdorff (2000). The role of the industry shifted increasingly from central public sector undertakings to multinational corporations and domestic information technology industry firms (Figures $1 \& 2$ ).

However, in Hyderabad, the transition from the first phase to the second phase was neither smooth nor spontaneous. Though Hyderabad, similar to Bangalore, had emerged as a cluster of modern manufacturing industries by the 1980s, it was the explicit initiative taken by the State (regional government) since the late 1990s for the transformation of the city towards the creation of a knowledge society and the positive response from the multinational corporations in the information technology industry, duly supported by domestic informa- 


\section{Comparing the Entrepreneurial Ecosystems for Technology Startups in India}

\section{H Bala Subrahmanya}

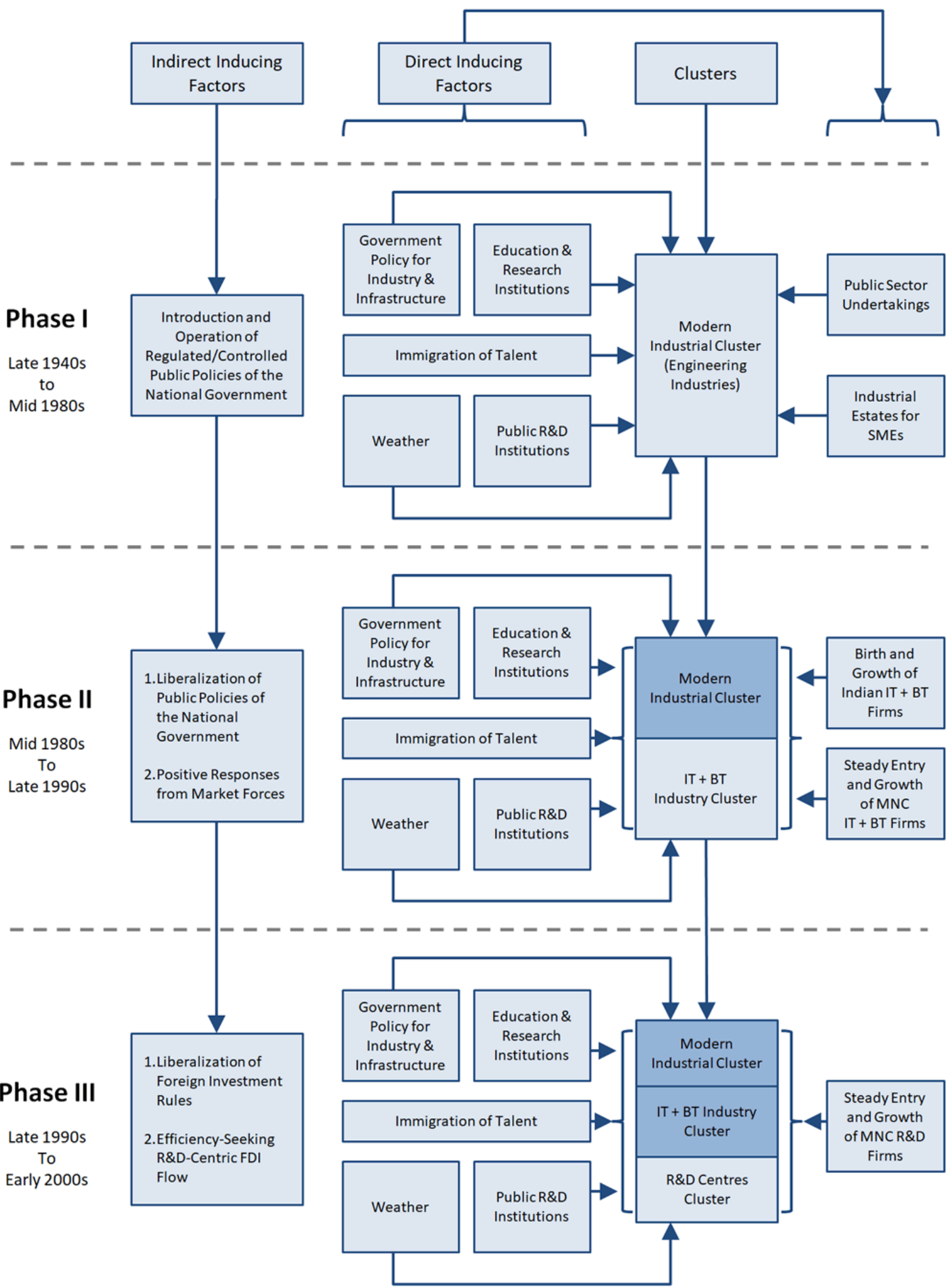

Figure 1. Bangalore: Phases in the evolution of its entrepreneurial ecosystem for technology startups 


\section{Comparing the Entrepreneurial Ecosystems for Technology Startups in India}

\section{H Bala Subrahmanya}

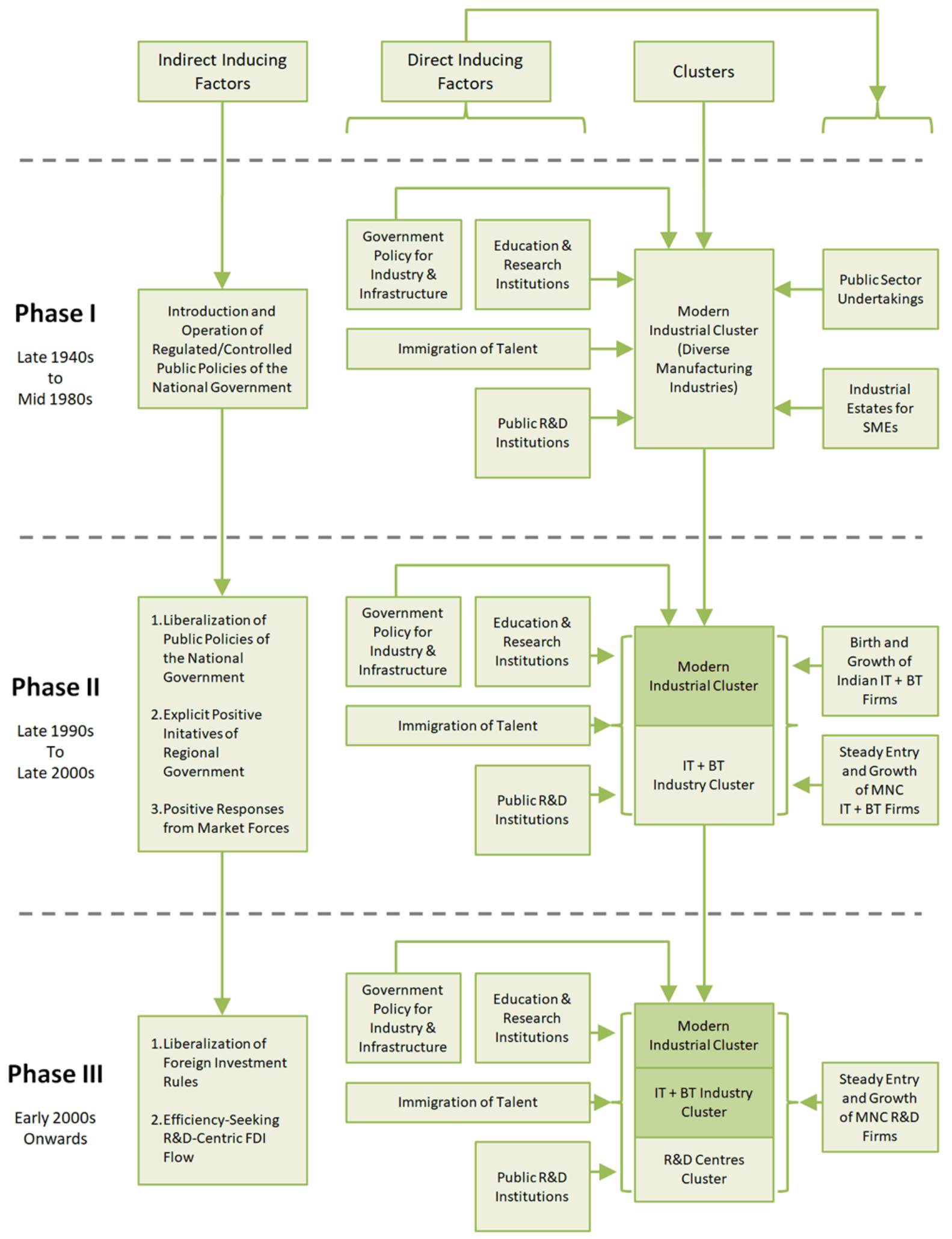

Figure 2. Hyderabad Phases in the evolution of its entrepreneurial ecosystem for technology startups 


\section{Comparing the Entrepreneurial Ecosystems for Technology Startups in India}

\section{H Bala Subrahmanya}

tion technology industry firms, which led to the emergence and growth of an information technology industry cluster in the subsequent decade (Das, 2015). Further, unlike Bangalore, Hyderabad had a heavy concentration of pharmaceutical industries and a higher concentration of biotechnology industries; both had come up (in 1980s as well as 1990s) prior to the emergence and growth of the information technology industries. The State (regional government in the place of national government) continued to be the dominant partner with industry and academia, implying that the "statist model" continued to be relevant for Hyderabad, unlike Bangalore, even in the second phase. Only the role of industry shifted from central public sector undertakings to multinational corporations and domestic private firms, and the role of academia was strengthened by the addition of private sector academic institutions (Figures 1 \& 2).

The transition from the second phase to the third phase, again, has taken place smoothly and spontaneously since the late 1990s in Bangalore, with more and more multinational corporations locating their R\&D affiliates in the city. This, coupled with the already established publicly funded $R \& D$ institutions, facilitated the emergence of an $R \& D$ cluster. In the process, interactions through partnerships and networking initiatives between $R \& D$ affiliates of multinational corporations and information technology industry development centres, academia and government grew. Perhaps all this led to the emergence of Bangalore as one of the 46 Global Hubs of Technological Innovation (UNDP, 2001) and the more recent identification of the city by the MIT Technology Review as one of the eight largest technology innovation clusters in the world (Times of India, 2013). Considering this, Bangalore might be in the process of witnessing what Etzkowitz and Leydesdorff (2000) have described as a "balanced" triple helix model (Figure 1). Though Hyderabad, similar to Bangalore, started to attract multinational corporations to locate their $R \& D$ affiliates, it is still in the process of catching up with Bangalore as a cluster for R\&D centres (Figures $1 \& 2$ ). Given this, Hyderabad might take some more time to witness a "balanced" triple helix model.

The question is, what is the relevance of the triple helix model and its different configurations for an entrepreneurial ecosystem for technology startups? It is the triple helix of university-industry-government interactions that generates knowledge and innovations (Ranga \& Etzkowitz, 2013), which could lead to the emergence and growth of technology-based startups. In addition, along with technology startups, triple helix interactions provide or influence all the required components of an entrepreneurial ecosystem for technology startups such as: i) sources of entrepreneurship; ii) sources of finance; iii) market; iv) human resources; v) support structure comprising accelerators, technology business incubators, and co-working spaces, among others; vi) mentorship; vii) policy; viii) conducive culture; and ix) supportive media. From the triple helix interactions, both Bangalore and Hyderabad have witnessed the emergence of these components in varying degrees.

In addition, weather has played a distinctly positive role in the case of Bangalore. Bangalore's strong point is its favourable weather, which helps foster a culture of optimism and openness, as stated by the MIT Technology Review (Times of India, 2013). Its location over the Deccan Plateau at an altitude of more than $3000 \mathrm{ft}$ above the sea level keeps it cooler than most other Indian cities, and gives it possibly the best climate among all the metropolitan cities of India. It is often stated that Bangalore enjoys a salubrious climate all through the year (Sudhira et al., 2007). This favourable weather has contributed significantly in attracting investments and technology workforce to the city on a continuous basis. Given this, it is appropriate to understand the structure of entrepreneurial ecosystems in the two technology startup hubs.

\section{Structure and Components of the Entrepreneurial Ecosystems of Bangalore and Hyderabad}

The more than six decades' growth of Bangalore, which saw the setting up of central public sector undertakings comprising modern manufacturing industries in machinery and electronics, coupled with the growth of much needed SMEs, educational institutions, public $R \& D$ institutions, followed by information technology and biotechnology industries, and then by R\&D affiliates of multinational corporations, ensured the emergence and growth of triple helix model partners, namely, government, industry, and academia. This gradually but steadily led to the emergence of different components of the entrepreneurial ecosystems for technology startups. Bangalore's current entrepreneurial ecosystem for technology startups is summarized in Figure 3 . The ecosystem can be broadly viewed as a system within the triple helix model comprising: i) a nucleus of technology startups and prospective technology startups, surrounded by the existence of ii) indispensable (primary) factors consisting of sources of finance including seed funds, angel investors, venture capital funds, and private equity firms; market support; human 


\section{Comparing the Entrepreneurial Ecosystems for Technology Startups in India}

\section{H Bala Subrahmanya}

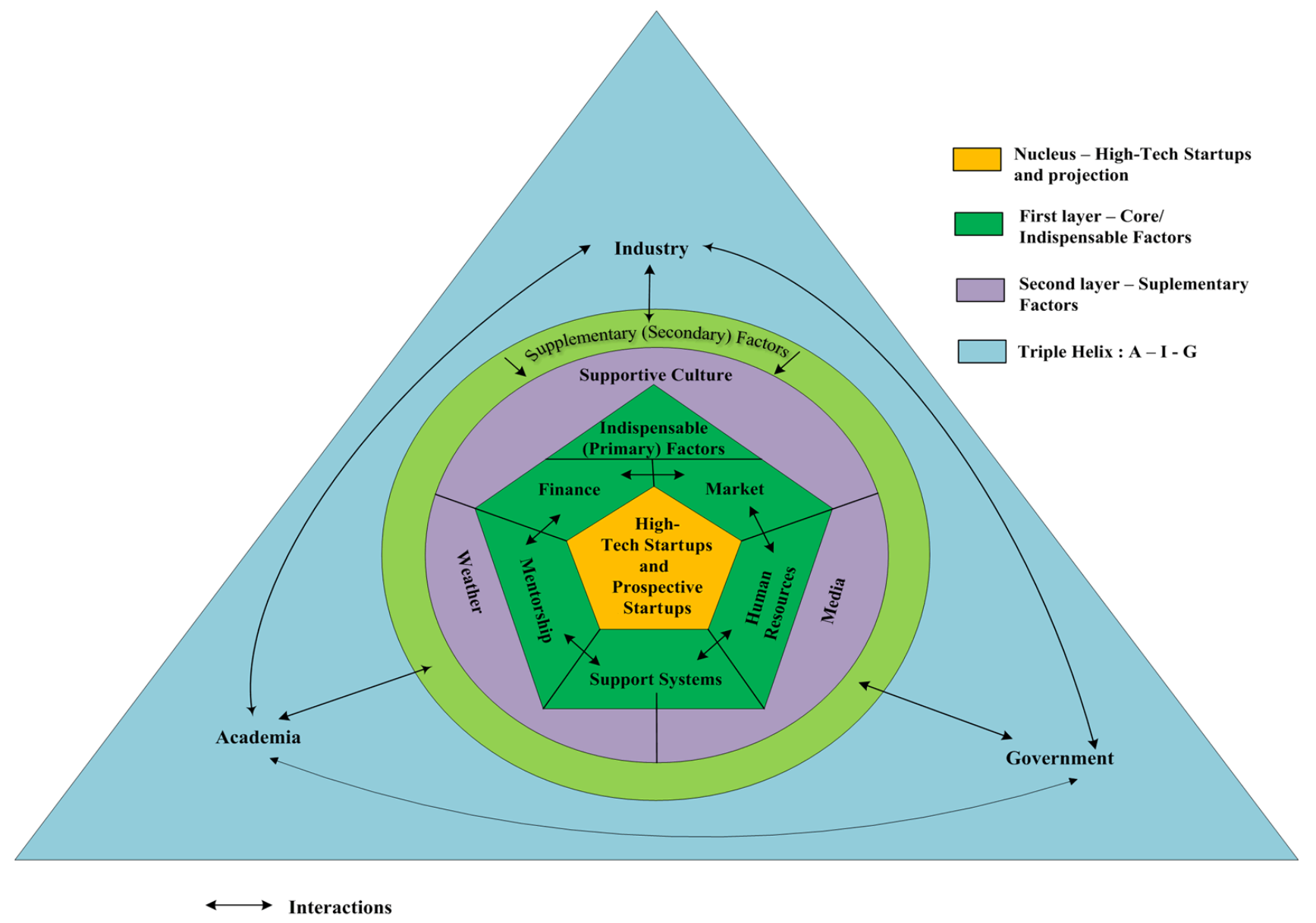

Figure 3. Bangalore: Structure and components of the entrepreneurial ecosystem for technology startups in relation to the triple helix model

resources, support systems in the form of accelerators, incubators, and co-working spaces; and technology and business mentors, and iii) supplementary (secondary) factors consisting of supportive culture (induced by constant talent immigration, supportive media and good weather).

The large base of education and research institutions in Bangalore play multiple roles in supporting and promoting the ecosystem. Karnataka state, of which Bangalore is the capital, has the third-largest concentration of professional (technical and management) education institutions and has one of the highest concentrations of universities and university-level institutes in the country (Government of India, 2016), the majority being located in Bangalore. First and foremost, these institutions generate entrepreneurial as well as human resource talent for technology startups. Second, faculty members in these institutions provide mentorship and sometimes even facilitate market support as the early adopters of startup products/services. Third, some of these institutions (such as the Indian Institute of Science, the Indian Institute of Management Bangalore, the International Institute of Information Technology Bangalore, the Institute for Bioinformatics and Applied Biology, and the National Centre for Biological Sciences) have their own technology business incubators and arrange for other support services, such as intellectual property consultancy, to nurture entrepreneurship through technology innovation commercialization, particularly among their own faculty/would-be graduates.

Large firms, similar to education and research institutions, form an indispensable part of the ecosystem for various reasons. These include central public sector undertakings, domestic private firms, and multinational corporations. First, similar to education and research institutions, they generate entrepreneurial talent as 


\section{Comparing the Entrepreneurial Ecosystems for Technology Startups in India}

\section{H Bala Subrahmanya}

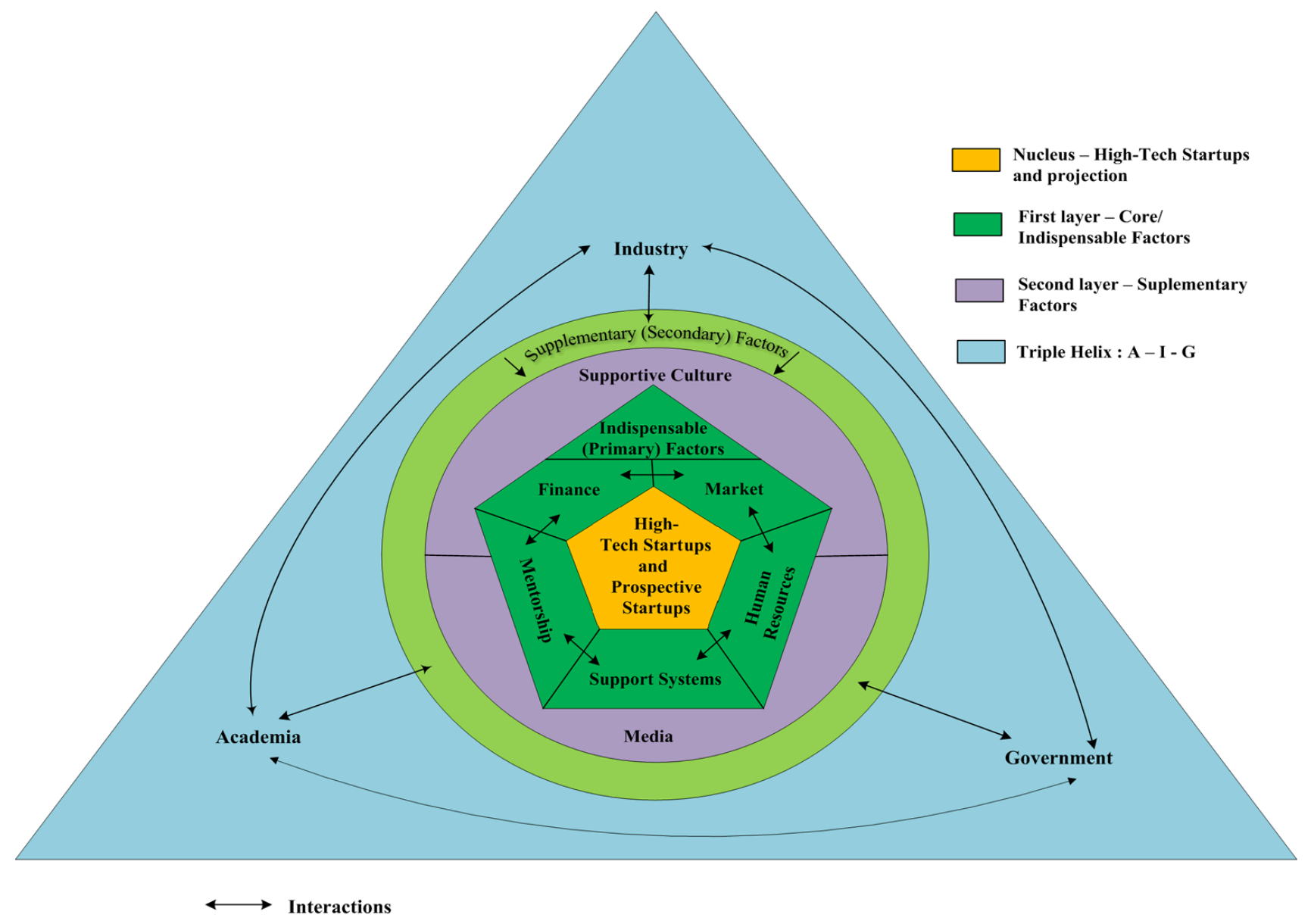

Figure 4. Hyderabad: Structure and components of the entrepreneurial ecosystem for technology startups in relation to the triple helix model

well as human resources for technology startups. The employees of large firms quit their jobs and enter the entrepreneurial world to implement their innovative ideas. Some of the multinational corporations explicitly encourage entrepreneurship among their employees by providing them sabbatical leave to experiment with their entrepreneurial ideas, with the option of returning to the company if the startup fails (ETB, 2016). Second, large firms provide early market support in the form of early adopters of startup products/services. Third, at times, they consciously nurture and promote startups through their own accelerators, with the objective of expanding market base for their own final products and services. Bangalore is home to many accelerators such as Kyron, Microsoft, SAP Labs, and Target. At a later stage, depending upon the "complementarity of business" and "compatibility of culture", they even acquire some of these startups.
India being a quasi-federal state, both the national government and the state government can play a direct or indirect role in the ecosystem for technology startups. The role of the national/regional government in startup promotion can be either passive or active. It can be passive if the government does not play any facilitating role. However, to begin with, immediately after independence, the national government located several key central public sector undertakings, public R\&D institutions, and universities in Bangalore. In the meantime, the regional government created the much-needed industrial infrastructure (in the form of power, industrial area development, communication, water, etc.) and stimulated modern industrialization. This was followed by the growth of information technology and biotechnology industries, and multinational corporations setting up $R \& D$ centres, apart from facilitating the establishment of education and research institutes. All 


\section{Comparing the Entrepreneurial Ecosystems for Technology Startups in India}

\section{H Bala Subrahmanya}

this led to an incessant inflow of talent from diverse corners of India.

Now, regional government appears to be an active facilitator of technology startups through the creation of support infrastructure such as venture capital funds and technology business incubators, though not on a considerable scale. But, the role of the government as an early adopter of startup products/services is hardly visible. More importantly, the Government of Karnataka (2015) has recently come out with an exclusive policy for startups to give them a further boost. It is the triple helix consisting of the academia-industry-government combination and its interactions which led to the gradual and steady emergence of a nucleus with a set of indispensable (primary) ecosystem components and supplementary (secondary) components.

The more than six decades' growth of Hyderabad, similar to Bangalore, saw the setting up of central public sector undertakings comprising a wide range of modern manufacturing industries such as machinery, electronics, and pharmaceuticals, coupled with the growth of much needed SMEs, educational institutions, and public R\&D institutions. This was followed by the emergence and growth of information technology and biotechnology industries, and of late, by R\&D affiliates of multinational corporations. This has resulted in the emergence and growth of triple helix model partners, namely, government, industry, and academia. All this has gradually and steadily led to the nurturing of different components of entrepreneurial ecosystem for technology startups. Hyderabad's current entrepreneurial ecosystem for technology startups is summarized in Figure 4 . The ecosystem can be broadly viewed, similar to Bangalore, as a system within the triple helix model comprising: i) a nucleus comprising technology startups and prospective technology startups, surrounded by the existence of ii) indispensable (primary) factors (finance, market, human resources, support systems, and mentors), and iii) supplementary (secondary) factors involving supportive culture and media. The role of weather, unlike in Bangalore, is not explicitly visible in the context of Hyderabad.

Hyderabad is the home for several national-level education and research institutions, which play multiple roles in supporting and promoting the ecosystem. First, these institutions are the sources of entrepreneurship and human resources for technology startups. Second, these institutions provide mentorship and sometimes even facilitate market support for product testing as well as acting as early adopters of startup products/services. Third, some of these institutions (such as the International Crops Research Institute for the Semi-Arid Tropics, the International Institute of Information Technology Hyderabad, the University of Hyderabad, the IKP Knowledge Park, and the Birla Institute of Technology and Science Pilani) have their own technology business incubators and arrange for other support services including intellectual property consultancy, to nurture innovation and entrepreneurship through technology commercialization, particularly among their own faculty/would-be graduates. More recently, the Indian Institute of Technology Hyderabad (which was started in 2008) initiated its own technology business incubator.

Large firms, particularly multinational corporations, form another indispensable part of the ecosystem for various reasons. These include central public sector undertakings, domestic private firms, and multinational corporations. First, similar to Bangalore, they generate entrepreneurial talent as well as human resources for technology startups. The employees of large firms quit their jobs and enter the entrepreneurial world to implement their innovative ideas or they fund promising entrepreneurial ideas as angel investors. Second, large firms provide early market support in the form of early adopters of startup products/services that have business compatibility. Third, at a later stage, depending upon the "complementarity of business" and "compatibility of culture", they undertake mergers and acquisitions of some of these startups. Thus, large firms provide the much-needed direct and indirect support for technology startups such as entrepreneurship, market, finance and human resources.

Like in Bangalore, to begin with, immediately after the independence, the national government located several key central public sector undertakings, public R\&D institutions, and universities in Hyderabad. During this time, the regional government was not visibly active in promoting industrialization. However, since the late 1990s, the state government has taken a pro-active stand for the promotion of information technology industries through the explicit development of specific infrastructure, while pharmaceutical and biotechnology industries have already registered their presence along with the growth of other manufacturing industries (Das, 2015). The process of setting up of R\&D centres by multinational corporations began much later. Slowly and steadily, this led to an incessant inflow of talent, though not to the extent of Bangalore, from diverse corners of India. 


\section{Comparing the Entrepreneurial Ecosystems for Technology Startups in India}

\section{H Bala Subrahmanya}

As of now, the regional government is an active facilitator of technology startups (much more than that of Bangalore) through the creation of support infrastructure. The setting-up of T-Hub (t-hub.co) in 2015, the largest technology business incubator in the country, represents just one example of the positive initiatives taken by the state government. T-Hub is designed for technology startups with the mission to catalyze the creation of one of the most vibrant entrepreneur communities in the world to encourage and fuel more startup success stories. It is a unique public-private partnership between the Government of Telangana and three premier institutes, namely, the International Institute of Information Technology Hyderabad (IIITH), the Indian School of Business (ISB), Hyderabad, and the National Academy of Legal Studies and Research (NALSAR) University, Hyderabad. It stands at the intersection of the startup, academic, corporate, research, and government sectors (T-Hub, 2016). The regional government has recently brought out an Innovation Policy and an Information \& Communication Technology Policy, respectively which, among others, focused on the promotion of technology startups (Government of Telangana, 2016a; Government of Telangana, 2016b). Thus, similar to Bangalore, it is the triple helix consisting of academia-industry-government combination and its interactions that resulted in the gradual and steady growth of a nucleus with a set of indispensable (primary) ecosystem components and supplementary (secondary) components.

A summary of the similarities and the differences between Bangalore and Hyderabad, the two promising but evolving technology startups hubs of India, is presented in Table 4.

Table 4. Similarities and differences between the Bangalore and Hyderabad ecosystems

\section{Similarities}

\section{Differences}

The ecosystem foundation was laid after India's independence in 1947 for Bangalore and after the accession of Hyderabad to India in 1948 for Hyderabad. The public policies of the national government, supplemented by that of regional governments, subsequently played a key role in each ecosystem.

Three distinct phases are ascertained in the evolution of entrepreneurial ecosystems for technology startups in both the cities.
The period of emergence of the second phase as well as that of the third phase in Bangalore is distinctly different from that of Hyderabad.

\begin{abstract}
The positive response of market forces to economic policy reforms played a major role in the early emergence of an information technology and biotechnology cluster followed by an $R \& D$ cluster in Bangalore, whereas pro-active regional government initiatives followed by market force responses played a major role in the subsequent emergence of the information technology and biotechnology cluster followed by an R\&D cluster in Hyderabad.
\end{abstract}

The modern industrial cluster followed by the information technology and biotechnology cluster and then by the R\&D centre cluster led to the gradual evolution of an ecosystem structure and its components.

The structure and components of entrepreneurial ecosystems in both the cities are observed to be largely similar, but for the role of weather which stands apart in the context of Bangalore.

Both the ecosystems are in the process of emerging and therefore in the "phase of evolving".
Weather played a distinct positive role in the emergence of an entrepreneurial ecosystem in Bangalore, whereas weather has not played any explicit role in Hyderabad.
Bangalore accounts for the highest number of unicorn companies in the country whereas Hyderabad has none, at present.

Bangalore accounts for a higher concentration of early stage startups and "cockroaches" relative to Hyderabad due to a higher level of vibrancy in the ecosystem. Accordingly, it is considered to be ahead of Hyderabad in the "quantity and quality" of ecosystem components and their interactions and therefore has a higher level of maturity relative to the latter. 


\section{Comparing the Entrepreneurial Ecosystems for Technology Startups in India}

\section{H Bala Subrahmanya}

\section{Conclusion}

Entrepreneurial ecosystems for technology startups are unique and they do not emerge overnight. The emergence of such ecosystems takes place over a period of time. Among the economies across the world, India occupies a unique place as an emerging economy, accounting for the third highest concentration of technology startups and startup exits globally. In India, Bangalore has been attracting global attention increasingly, and more recently, as a hub of technology startups. Hyderabad, as one of the fast-emerging technology startup hubs in India, is closely following Bangalore. Given this, two questions are answered in this article: How did the entrepreneurial ecosystems of these two cities emerge over a period of time? and What is the structure of these ecosystems and what are their components?

The seeds for the emergence of the two ecosystems were sown immediately after India's independence in 1947 for Bangalore and after accession into Indian Union in 1948 for Hyderabad. Public policy driven central public sector undertakings, public R\&D institutions, educational institutions, supplemented by domestic private enterprises led both the cities to emerge as modern industrial clusters. This was followed by the entry of multinational corporations in the information technology and biotechnology industries in response to economic liberalization (in Bangalore) and in response to regional government initiatives (in Hyderabad), which resulted in the emergence of information technology/biotechnology clusters. Subsequently, a steady liberalization of foreign investment rules and regulations encouraged a steady entry of R\&D affiliates of multinational corporations in Bangalore, followed by in Hyderabad, which nurtured clusters of R\&D centres. It is the successive addition of these three different but inter-related clusters that gradually and steadily led to the rise of various components of entrepreneurial ecosystems in the two cities with a strong base of government-industry-academia triple helix model.

Today, the entrepreneurial ecosystems of both Bangalore and Hyderabad have all the critical components that have been commonly identified in empirical literature in the international context. In addition, the diverse stakeholders of the two ecosystems enabled us to define the structure of an ecosystem in the Indian context. The triple helix model comprising government, industry, and academia formed the foundation of the ecosystem, within which the system involved a nucleus comprising technology startups and prospective tech- nology startups with two outer layers. The first outer layer consisted of five primary (indispensable) factors (namely, finance, market, human resources, mentors, and support systems), whereas the outer-most layer comprised three secondary (supplementary) factors of culture, media and weather (in the case of Bangalore), culture and media (in the case of Hyderabad).

However, the ways the triple helix model operates in the two cities are different. Whereas in the Bangalore ecosystem, the triple helix interactions appear to have graduated from a "statist" model to a "laissez-faire" model and further to a "balanced" triple helix model, in the Hyderabad ecosystem, a "statist" model seems to be relevant even today. This is primarily because industry and academia have emerged, over a period of time, to be as important as the government, if not more, in Bangalore. But government continues to be the dominant partner in Hyderabad even today, due to its pro-active ecosystem promotional policies. This has been corroborated by our interviewed stakeholders in both the cities. But what does it imply?

Broadly, an ecosystem for startups is assumed to graduate through four different stages of evolution: i) nascent, ii) evolving, iii) mature, and iv) self-sustainable (Cukier et al., 2016). Considering that the vibrancy of both Bangalore and Hyderabad ecosystems is largely confined to a rapidly growing "emergence of technology startups", followed by a number of "stably operating" startups but with few "successful and grown" startups, it would be appropriate to conclude that these two ecosystems are still "evolving", and therefore, have only "moderately matured". Recently, in terms of the growth index for startup hubs, Bangalore has been ranked at the top internationally, followed by London and Tel Aviv (Velayanikal, 2015). The balanced triple helix model would prove beneficial to take Bangalore further towards maturity in the coming years. But the same cannot be assumed to happen in the case of Hyderabad. Only the continued active involvement of the government might ensure its further evolution towards maturity. In other words, any withdrawal or reduction in the role of the government might affect the further evolution of the Hyderabad ecosystem towards maturity.

Given the above, what are the key lessons/insights that we can derive from the experiences of Bangalore and Hyderabad for elsewhere in India and the world? The findings of our analysis yield three important lessons. First, the evolution of an entrepreneurial ecosystem in a technologically vibrant innovation cluster (Bangalore, which is often compared with a developed economy 


\section{Comparing the Entrepreneurial Ecosystems for Technology Startups in India}

\section{H Bala Subrahmanya}

cluster) and an emerging innovation cluster (Hyderabad) within an emerging economy (India) is historically explored and analyzed. The critical factors that led to the laying of an ecosystem foundation gradually and steadily over a period of almost six decades in three different phases, along with other supportive factors are brought out. This finding clearly demonstrates that ecosystem development is an evolving process. But, this process will neither evolve naturally nor can it be built by design. As argued by Isenberg (2011), ecosystems are usually the result of intelligent evolution (a process that blends the invisible hand of markets and the deliberate helping hand of public policies).

Second, an entrepreneurial ecosystem is essentially regional in character. The present study has revealed the unique features and elements involved in the development of the Bangalore and Hyderabad ecosystems. An entrepreneurial ecosystem is unique as it is the result of multiple elements interacting in highly complex and idiosyncratic ways, as brought out by these two cases. Though the Bangalore and Hyderabad ecosystems have some similarities, they are not identical. This finding highlights that it is neither feasible nor desirable to replicate either Bangalore or Hyderabad, even within India. What is essential is to ascertain and understand the structure and critical components of an entrepreneurial ecosystem, without which an ecosystem might not emerge, even if it emerges it may not survive, and even if it survives it may not prove to be effective or successful.

Third, the structure and critical components of Bangalore and Hyderabad entrepreneurial ecosystems are ascertained. The triple helix comprising government, industry, and academia form the basis for an entrepreneurial ecosystem as it supports or generates the critical components of an entrepreneurial ecosystem. An entrepreneurial ecosystem for technology startups is defined as a structure with the triple helix as the base, and it comprises a nucleus (startup entrepreneurs and prospective entrepreneurs) with two outer layers consisting of some core and indispensable components as the first outer layer, which include: i) financiers (in the form of seed funds, angel investors, venture capitalists, and private equity firms), ii) markets, iii) human resources, iv) nurturers (in the form of accelerators, business in- cubators, and co-working spaces), and v) business and technology mentors. The second outer layer consists of supplementary factors such as supportive culture, effective media, and, if possible, good weather. Thus, the nucleus and the core components, supplemented adequately by the secondary factors, and with the triple helix as the base, define the structure of an ecosystem for technology startups. Their adequate and growing presence and interactions will generate vibrancy in the ecosystem for its further growth. This would lead to an increasing scale of technology startup emergence, nurturing for survival and stability, and growth of the successful ones, thereby contributing to national economic growth, innovation achievements, and employment generation.

\section{Acknowledgements}

This study forms a part of the research project titled "A Study on the Ecosystem for High-Technology Startups in Bangalore and Hyderabad", which is sponsored by the Department of Science and Technology (DST), Government of India, New Delhi. DST Project F.No. DST/NSTMIS/05/178/2014-15.

\footnotetext{
About the Author

M H Bala Subrahmanya is a Professor of Economics in the Department of Management Studies at the Indian Institute of Science (IISc), Bangalore, India. He joined Indian Institute of Science, Bangalore as an Assistant Professor in 1996, was promoted to Associate Professor in 2002, and further to a Professor in 2008. He has more than 27 years of professional experience, of which more than 21 years are at the IISc. During his professional career, he received a Commonwealth Fellowship (1999-2000), a Japan Foundation Fellowship (2004/2005), and a FulbrightNehru Senior Research Fellowship (2009/2010). He holds a PhD in Economics from the Institute for Social \& Economic Change (ISEC) in Bangalore, and his field of specialization is Industrial Economics.
} 


\section{Comparing the Entrepreneurial Ecosystems for Technology Startups in India}

\section{H Bala Subrahmanya}

\section{References}

Aaltonen, A. .2016. Factors Shaping Entrepreneurial Ecosystems and the Rise of Entrepreneurship: A View from Top Management Journals. Helsinki: Demos Helsinki.

Aleisa, E. 2013. Startup Ecosystems: Study of the Ecosystems Around the World; Focusing on Silicon Valley, Toronto and Moscow. Project Report.

http://www.janrecker.com/wp-

content/uploads/2013/02/20130213_FinalReport_Startup-

Ecosystems.pdf

Anju, Z. 2014. Startup Capitals: Discovering the Global Hotspots of Innovation. Gurgaon, India: Random House.

Arruda, C., Nogueria, V. S., \& Costa, V. 2013. The Brazilian Entrepreneurial Ecosystem of Startups: An Analysis of Entrepreneurship Determinants in Brazil as Seen from the OECD Pillars. Journal of Entrepreneurship and Innovation Management, 2(3): 17-57.

Bala Subrahmanya, M. H. 2015. New Generation Startups in India: What Lessons Can We Learn from the Past? Economic and Political Weekly, 50(12): 56-63.

Certo, S. T. 2003. Influencing Initial Public Offering Investors with Prestige: Signalling with Board Structures. Academy of Management Review, 28(3): 432-446.

http://www.jstor.org/stable/30040731

Clarke-Billings, L. 2017. Bangalore Named Fastest-Changing and Most Dynamic City in the World. Newsweek, January 18, 2017. Accessed March 10, 2017: http://europe.newsweek.com/bangalore-fastest-changigdynamic-innovative-city-world-544166

Cukier, D., Kon, F., \& Lyons, T. S. 2016. Software Startup Ecosystems Evolution: The New York City Case Study. In Proceedings of 2nd International Workshop on Software Startups, IEEE International Technology Management Conference, Trondheim, Norway.

Dale, R., \& Zell, Z. 2014. Startup Ecosystems: A Look at Entrepreneurship in London and Boulder. Working Paper. London: FNCE.

Das, D. 2015. Hyderabad: Visioning, Restructuring and Making of a High-Tech City. Cities, 43: 48-58.

https://doi.org/10.1016/j.cities.2014.11.008

Department of Industries \& Commerce. 1996. Industrial Policy 1996-2001. Bangalore, India: Government of Karnataka.

DST. 2015. Directory of $R \& D$ Institutions 2015. New Delhi, India: National Science and Technology Management Information System, Department of Science and Technology, Government of India.

Etzkowitz, H. 2003. Innovation in Innovation: The Triple Helix of University-Industry-Government Relations. Social Science Information, 42(3): 293-337. https://doi.org/10.1177/05390184030423002

Etzkowitz, H., \& Leydesdorff, L. 2000. The Dynamics of Innovation: From National Systems and "Mode 2" to a Triple Helix of University-Industry-Government Relations. Research Policy, 29(2): 109-123. https://doi.org/10.1016/S0048-7333(99)00055-4
Foster, G., \& Shimizu, C. 2013. Entrepreneurial Ecosystems Around the Globe and Company Growth Dynamics. Cologny, Switzerland: World Economic Forum.

Gai, B., \& Joffe, B. 2013. India Startup Report. World Startup Report. http://www.worldstartpreport.com

Government of Karnataka. 2015. Karnataka Startup Policy 2015-2020. Department of Information Technology, Biotechnology and Science \& Technology. Bangalore, India: Government of Karnataka.

Government of Telangana. 2016a. Innovation Policy 2016. Telangana, India: Department of Information Technology, Electronics and Communications, Hyderabad.

Government of Telangana. 2016b. ICT Policy Framework 2016. Department of Information Technology, Electronics and Communications, Hyderabad.

Haines, T. 2016. Developing a Startup and Innovation Ecosystem in Regional Australia. Technology Management Innovation Review, 6(6): 24-32.

https://timreview.ca/article/994

Hemmert, M., Cheng, Y., Kohlbacher, F., Kotosaka, M., Loh, C. T., \& Waldnberger, F. 2016. High-tech Startup Ecosystems in East Asian Agglomerations: Are They Different from the West? Tokyo: German Institute of Japanese Studies.

Isenberg, D. 2011. The Entrepreneurship Ecosystem Strategy as a New Paradigm for Economic Policy: Principles for Cultivating Entrepreneurship. Babson Park, MA: Babson Entrepreneurship Ecosystem Project, Babson College.

Kane, T. 2010. The Importance of Startups in Job Creation and Job Destruction. Working Paper. Kansas City, MI: Kauffman Foundation Research Series: Firm Formation and Economic Growth.

Krajcik, V., \& Formanek, I. 2015. Regional Startup Ecosystem. European Business \& Management, 1(2): 14-18. http://dx.doi.org/10.11648/j.ebm.20150102.12

Motoyama, Y., \& Watkins, K. 2014. Examining the Connections within the Startup Ecosystem: A Case Study of St. Louis. Kansas City, MI: Kauffman Foundation.

NASSCOM. 2015. Startup India: Momentous Rise of the Indian Startup Ecosystem. Bangalore, India: Zinnov Consulting.

OECD. 2013. Startup Latin America: Promoting Innovation in the Region. Paris: Development Centre Studies.

Office of the Registrar General \& Census Commissioner, India. 2011. Census of India. New Delhi, India: Government of India.

Piscione, D. P. 2013. Secrets of Silicon Valley: What Everyone Else Can Learn from the Innovation Capital of the World. London: Macmillan.

Pullen, J. P. 2013. Emerging Tech: 9 International Startup Hubs to Watch. Entrepreneur, May 7, Business Daily, USA.

Ranga, M., \& Etzkowitz, H. 2013. Triple Helix Systems: An Analytical Framework for Innovation Policy and Practice in the Knowledge Society. Industry and Higher Education, 27(4): 237-262. https://doi.org/10.5367/ihe.2013.0165

Sean, TAN C S. 2015. Startup Ecosystem in Singapore. Working Paper. The Netherlands: Rijksdienst voor Ondernemend Nederland. 


\section{Comparing the Entrepreneurial Ecosystems for Technology Startups in India}

\section{H Bala Subrahmanya}

Stangler, D., \& Masterson, J. B. 2015. Measuring an Entrepreneurial Ecosystem. Kansas City, MI: Kauffman Foundation.

Startup Genome. 2015. Startup Ecosystem Report 2015. San Francisco, CA: Startup Genome.

Sudhira, H. S., Ramachandra, T. V., \& Bala Subrahmanya, M. H. 2007. City Profile: Bangalore, Cities. The International Journal of Urban Policy and Planning, 24(5): 379-390.

T-Hub. 2016. T-Hub. Accessed July 1, 2017: http://t-hub.co

Times of India, 2013. Bengaluru Among Top 8 Technology Innovation Clusters. Times of India, August 2, 2017. Accessed July 1, 2017: http://economictimes.indiatimes.com/tech/ites/bangaloreamong-top-8-technology-innovationclusters/articleshow/21546192.cms

Times of India. 2016. India Ranks Third in Tech Startup Exits. Times of India, September 22, 2017. Accessed July 1, 2017:

http://timesofindia.indiatimes.com/business/indiabusiness/India-ranks-3rd-in-tech-startupexits/articleshow/54453645.cms

UNDP. 2001. Human Development Report 2001. New York: Oxford University Press, United Nations Development Programme (UNDP).

World Economic Forum. 2014. Entrepreneurial Ecosystems around the Globe and Early-Stage Company Growth Dynamics. Geneva, Switzerland: World Economic Forum.

Citation: Bala Subrahmanya, M. H. 2017. Comparing

the Entrepreneurial Ecosystems for Technology

(cc) BY

Startups in Bangalore and Hyderabad, India.

Technology Innovation Management Review, 7(7):

47-62. http://timreview.ca/article/1090

Keywords: startups, technology, ecosystems,

entrepreneurship, Bangalore, Hyderabad, India 